\title{
Búsquedas de vínculos eróticos y/o afectivos a través de las apps. Un estudio comparado entre la Ciudad de Buenos Aires y la Ciudad de México
}

Mariana Palumbo

UBA/CONICET

\section{Resumen}

El artículo analiza, desde un enfoque cualitativo y de corte comparativo, por qué mujeres y varones heterosexuales adultas de clase media residentes de la Ciudad de Buenos Aires y de México eligen a las aplicaciones de citas, en este caso Tinder, como el espacio de sociabilidad a partir del cual llevar a cabo encuentros eróticos y/o afectivos. Para tal fin se describen y analizan: a) cuáles son las motivaciones - facilidades propias de la aplicación y aquellas de índole erótica y/o afectiva- que lleva a sus usuarios/as a utilizar Tinder; b) el uso geolocalizado que la aplicación ofrece: dónde sus usuarios/as la usan, cuáles son sus márgenes espaciales de búsqueda y cuál es su uso en otros países si los hubiera; c) el papel de las mujeres como consumidoras de las aplicaciones virtuales de citas.

\footnotetext{
Abstract

This article employs a qualitative and comparative approach towards analyzing the reasons why middle-class adult heterosexual men and women residing in Buenos Aires and Mexico choose to use dating applications -in this case Tinder- as a space of sociability for the purpose of erotic and/or affective meetings. To that end, we shall describe and analyze: a) the motivations involved -conveniences, as well as erotic and/or affective features of the application- that attract users to Tinder; b) the geolocation feature offered by Tinder: where the application is used, the spatial scope of
}

Palabras claves:

aplicaciones de citas; búsquedas; vínculos eróticos y/o afectivos; motivaciones; heterosexualidad
Keywords:

dating apps; searches; erotic and/or affective encounters; motivations; heterosexuality 
1. Las ciudades globales son nudos de la economía global, en las mismas se integran economías regionales, nacionales e internacionales. Las ciudades globales no se definen ni por fronteras administrativas ni por el tamaño de su población, sino por sus funciones en la economía mundial. Son centros a través de los cuales los flujos de capital, información, mercancías y migrantes circulan, y desde donde se controlan y gestionan estos flujos (Parnreiter, 2002: 90).

2. La crisis de diciembre de 2001 en Argentina fue una crisis económica, social, política e institucional que causó la renuncia del entonces presidente de Argentina Fernando de la Rúa. the searches performed, and if the application is used in other countries; c) the role of women as consumers of dating applications.

\section{Introducción}

La Ciudad de Buenos Aires y la ciudad de México son los dos conglomerados urbanos hispanohablantes más grandes de América Latina y ambos pueden ser considerados como ciudades globalizadas ${ }^{1}$ (Parnreiter, 2002). Algunas de las características que comparten es que tanto una como la otra se insertan en un contexto de modernidad tardía signado por la aparición de nuevos modelos de organización del trabajo y el corrimiento de las instituciones estatales en tanto productoras del lazo social (Beck, 1998).

En la modernidad tardía las personas están desligadas de los modelos tradicionales de la sociedad industrial en relación con el saber hacer, las creencias y las normas orientativas. En América Latina, desde 1990, los procesos económicos han aumentado la desigualdad social y existe una tendencia regresiva en la distribución del ingreso y una creciente polarización social (Jelin, 2010). Esto se observa en reformas legales que han flexibilizado las relaciones laborales, aumento de la desocupación y pérdida del poder adquisitivo de los sectores medios y bajos.

Este proceso se ha dado de manera diferenciada en los distintos países de la región. En México desde la década de 1980, durante el gobierno de Miguel de la Madrid (1982-1988), se han instaurado políticas neoliberales que aún hoy continúan e intensifican (Encinas Ferrer, 2009; Salazar, 2004). Asimismo, este país experimenta problemas crecientes de narcotráfico, violencia y desaparición de personas. Mientras que en el caso argentino, luego de la crisis social, política y económica del año $2001,{ }^{2}$ los gobiernos de Néstor Kirchner (2003-2007) y Cristina Fernández (2007-2011 y 20112015) si bien no desmantelaron la totalidad de las políticas neoliberales que se comenzaron a implementar desde la última dictadura militar de 1976 y que se instauraron de manera más exhaustiva durante la década de 1990, apuntaron a la centralidad del Estado y a la expansión de la democracia en el sentido de politización y demanda en el espacio público de diferentes sectores sociales (Caetano, 2010; Cheresky, 2011). No obstante, desde el gobierno de Mauricio Macri, electo en el año 2015, ha habido un nuevo avance de reformas de carácter neoliberal.

Este contexto de flexibilización laboral y de encarecimiento de la vida cotidiana, a partir de la primacía acentuada de la esfera del mercado por sobre la estatal, impacta en la subjetividad de las personas. De manera creciente los individuos se encuentran a merced de sus propios medios, en distintos niveles de su vida. Prima lo que Beck (1998) llama un modelo biográfico de realización personal en el cual son los sujetos quienes deben proveerse y negociar su bienestar, en términos individuales. En el nivel erótico y afectivo, la búsqueda de vínculos ideales acordes a sus intereses lleva a que las trayectorias afectivas de las personas sean zigzagueantes y heterogéneas. En términos demográficos se observa que México y Argentina se encuentran, con sus matices y diferencias, dentro del proceso de segunda transición demográfica, el cual implica una mayor cantidad de divorcios y separaciones de uniones de hecho, una disminución de la cantidad de números de hijos/as y postergación de la maternidad, principalmente en mujeres de clase media y alta, como así también un aumento de número de personas que viven solas. Asimismo, se incrementó la cantidad de hogares encabezados por mujeres y de madres solteras ya sea por elección o por el abandono paterno (Cerrutti y Binstock, 2009; de Oliveira, 1995; . pAN ase media y 
altarementras ya sea por elecciivorcio y el envejecimiento. pAN 1994 Jelin, 1989, 2010; Pérez Amador, 2008).

Las soluciones de mercado han pasado a tener un lugar central y dentro de ellas se desarrolla la mercantilización de lo afectivo a partir de la existencia de servicios diseñados para los ámbitos emocionales de nuestras vidas (Elizalde y Felitti, 2015; Hakim, 2010; Hochschild, 1983; Illouz, 2012). Entre estos se hallan las aplicaciones virtuales de búsqueda de vínculos eróticos y/o afectivos ${ }^{3}$ en tanto son para sus usuarios/as una solución que facilita, temporal y espacialmente, sus búsquedas.

La proliferación del uso de sitios de citas se observa en las cifras que arroja por ejemplo la aplicación Tinder, ${ }^{4}$ en relación con la cantidad de usuarios/as y su nivel de uso. En el sitio web de Tinder se indica que a nivel global existen más de 50 millones de perfiles activos y que 1.6 billones son vistos por día. ${ }^{5}$ Según entrevistas a Andrea Iorio, director de Tinder para América Latina, la aplicación se encuentra disponible en 191 países y en 10 idiomas. Respecto a Latinoamérica, Brasil es el país que más utiliza la aplicación en la región y es el segundo a nivel global, luego de Estados Unidos. México y Argentina son los otros dos países de Latinoamérica donde más se usa la aplicación y ambos están en el top 10 a nivel mundial (Entrevista en Diario La Nación, 13 de febrero de 2016; entrevista en Radio Latina FM 101.1, 11 de febrero de 2016; entrevista en Imagen Radio, 14 de junio de 2016; entrevista Más Milenio, 17 de junio de 2016).

En resumen, se visualiza que las subjetividades en la modernidad tardía se encuentran atravesadas por una situación de mayor vulnerabilidad y de endeble inserción en el mercado de trabajo formal, condiciones que habilitan, en el nivel erótico y afectivo, una privatización de las actividades sociales. Prevalecen búsquedas y sociabilidades desde los espacios virtuales, signadas por la racionalización, de manera más dinámica y fugaz.

A la luz de este nuevo contexto, a partir de un análisis comparativo entre la Ciudad de Buenos Aires (Argentina) y la Ciudad de México (México), el siguiente artículo se propone examinar por qué las personas adultas de clase media urbana eligen a las aplicaciones de citas, en este caso Tinder, como el espacio de sociabilidad, a partir del cual llevar a cabo encuentros eróticos y/o afectivos. Para tal fin se describen y analizan: a) cuáles son las motivaciones -facilidades propias de la aplicación y aquellas de índole erótica y/o afectiva- que llevan a sus usuarios/as a utilizar Tinder; b) el uso geolocalizado que la aplicación ofrece: dónde sus usuarios/as la usan, cuáles son sus márgenes espaciales de búsqueda y cuál es su uso en otros países si los hubiera; c) el papel específico de las mujeres en tanto consumidoras de las aplicaciones virtuales de citas.

La elección del análisis de Tinder se basa en que encuentro que es la única aplicación, dentro de la multiplicidad de aplicaciones y sitios de citas disponibles, que se utiliza extensivamente tanto en México como en Argentina. Además de Tinder los/ as entrevistados/as que residen en Ciudad de México suelen usar Adoptaunchico (https://www.adoptaunchico.com.mx) o Bumble (https://www.bumble.com/es) y los/as argentinos/as, Happn https://www.happn.com/es).

La metodología de este artículo es de corte cualitativo. Realicé veinte entrevistas en profundidad: ${ }^{6}$ once fueron realizadas a mujeres (seis a mexicanas que residen en la Ciudad de México y cinco a argentinas que residen en la Ciudad de Buenos Aires) y nueve a varones (cuatro a mexicanos que residen en la Ciudad de México y cinco a argentinos que residen en la Ciudad de Buenos Aires). Los/as entrevistados fueron usuarios/as cis ${ }^{7}$ de la aplicación Tinder, mexicanos/as y argentinos/as, que no estu-
3. Respecto a mi planteo de "encuentros eróticos y/o afectivos": tiene como finalidad dar cuenta de la multiplicidad de búsquedas de vínculos que aparecen cuando las personas acceden a los espacios de sociabilidad analizados, tanto a los que son cara a cara como a los virtuales. Las personas entrevistadas pueden buscar desde encuentros eróticos a pareja, pasando por mera compañía o flirteo, sin relaciones sexuales.

4. Sitio Web Tinder: <https:// www.gotinder.com/press>

5. Tinder es una aplicación que permite a los/as usuarios/as, con cualquier tipo de orientación sexual e identidad de género, comunicarse con otras personas con base en sus preferencias para charlar y concretar citas o encuentros. Dispone de una interfaz de usuario que muestra sucesivamente diferentes perfiles de otros usuarios. El usuario desliza el dedo por sobre la pantalla de un Smartphone (teléfono inteligente)

o Tablet (tableta) a la derecha para indicar interés (marca un corazón) por esa persona y a la izquierda si no está interesado (marca una cruz), todo ello de forma anónima. Si dos usuarios están interesados en sí, ambos son informados, se establece lo que Tinder denomina como compatibilidad y se les permite iniciar la conversación a través del chat interno de la aplicación. Existen otras aplicaciones de similar uso como Happn.

6. Las entrevistas fueron pautadas a través de la técnica bola de nieve, a partir de contactos de conocidos/ as. En todo momento se respeto la confidencialidad y el anonimato. Los nombres que aparecen en este artículo son seudónimos.

7. "Cis" es una forma de indicar a las personas que no son trans. Es decir, aquellas que se identifican con Los términos cis y trans oponen dos prefijos latinos. "Cis" quiere decir "de este lado", mientras que "trans" significa "del otro lado" (Blumer, Ansara, Watson, 2013). Asimismo, a partir del prefijo cis se nombra a la mayoría dominante y se explicita que las identidades no trans también son construidas (Serano, 2016). 
8. Entiendo por personas separadas aquellas que han convivido sin casarse y ya no lo hacen. 9. Retomo la caracterización y tipología de clase media en la Argentina que desarrolla Sautu (2016), a partir su abordaje de dichos aspectos estructurales. La clase media comprende fracciones compuestas por ocupaciones que se desempeñan en el sector privado y en el sector público de la economía. Su rasgo común es que no se insertan donde está el poder económico y político, pero tampoco en el otro extremo de la estructura de clase. Los gerentes operativos, los profesionales, los propietarios y agentes de sector privado conforman la clase media junto con diversos niveles de la burocracia nacional, provincial, y municipal (Sautu, 2016: 180).

10. Si bien no desconozco la utilización de las aplicaciones de citas por parte de personas que están en pareja o casadas, dejo esa indagación para futuros trabajos. Entiendo que en esos casos el uso de las aplicaciones

posee lógicas propias, diferentes a

las de quienes buscan de manera abierta vínculos eróticos y/o afectivos.

11. Para obtener esta información creé un usuario de varón y otro de mujer y llevé a cabo una búsqueda en términos heterosexuales a personas dentro del rango de 30 a 50 años. Los usuarios que creé no marcaban preferenrios que cree no marcaban preferen-
cias, tenían como fotografías un paisaje de una nube y un sol - solo en el caso de aquellas aplicaciones que era obligatorio poner una imagen, sino no tenían imagen- no interactuaban con ningún usuario sino que simplemente fueron utilizados para observar los fueron utilizados para observar los perfiles, que son públicos, y las funciones que poseen las aplicaciones. viesen en un vínculo de pareja formal -solteros/as, separados/as ${ }^{8}$ o divorciados/as-, heterosexuales, de entre 30 y 50 años de sectores medios y que finalizaron sus estudios terciarios o universitarios ${ }^{9}$. Al momento de la entrevista los/as entrevistados/as trabajaban principalmente en relación de dependencia, para el ámbito público o privado, en oficinas, y residían en la Ciudad de Buenos Aires o en la Ciudad de México, respectivamente.

En relación con el recorte etario, de entre 30 y 50 años, elegido en este artículo se basa en tres razones: 1) si bien las mujeres y varones de sectores medios y altos tienden a retrasar el casamiento o nunca se casan, las uniones consensuadas son una práctica recurrente entre los/as heterosexuales/as de 25 a 34 años de edad, de Argentina y México (Cerruti y Binstock, 2009); 2) los cuarenta años se presentan como el "umbral" de la fertilidad femenina para el discurso médico hegemónico y para la cosmovisión de los propios sujetos; 3 ) la concentración de los divorcios, al momento de la sentencia, está dada en la Ciudad de Buenos Aires en los grupos de entre 35 y 44 años de edad (Dirección General de Estadística y Censos, Gobierno de la Ciudad de Buenos Aires, 2014) y para la Ciudad de México se observa que las mujeres se divorcian en una edad promedio de 38.9 años y los varones de 41.2 (Instituto Nacional de Estadística y Geografía de México, 2013). Es decir, teniendo en cuenta estos datos me propongo examinar las motivaciones del uso de Tinder de aquellos varones y aquellas mujeres de entre 30 y 50 años de edad que no tuvieron uniones consensuales o si las tuvieron no perduraron y cómo opera el "umbral" reproductivo femenino potenciando y desviando las búsquedas, tanto de mujeres como de varones. Asimismo, en tanto en este segmento etario es cuando se desarrollan la mayor cantidad de divorcios y separaciones, esto me lleva a preguntarme por los sentidos que le otorgan los sujetos al uso de Tinder cuando se reinsertan en el mercado erótico y/o afectivo. ${ }^{10}$

Asimismo, llevé a cabo observaciones a los perfiles de usuarios/as de Tinder. Las observaciones -solo de los perfiles públicos, pero no de sus conversaciones y coincidencias con otros usuarios, dado que estas son privadas- me permitieron analizar a la vez los criterios de selección de los sujetos, cómo se presentan en las imágenes, lo que escriben sobre ellos/as mismos/as y las referencias que hacen en relación a qué tipo de persona buscan y a qué tipo de vínculo erótico o amoroso desean. ${ }^{11}$

El artículo se divide en tres secciones, en la primera abordo el uso que le dan sus usuarios/as a Tinder teniendo en cuenta las facilidades que, según los/as que han manifestado las y los entrevistados/as, les ofrece la aplicación. Seguidamente indago en las expectativas que motivan su uso y, por último, analizo cuál es el papel de la agencia femenina en el uso de Tinder.

\section{Apreciaciones y facilidades en torno a Tinder}

Uno de los puntos en los cuales se centraron las entrevistas fue en por qué las personas eligen a Tinder como forma de sociabilizar erótica y/o afectivamente y como modo de sexualización. Los/as entrevistados/as de la Ciudad de México y de Buenos Aires, sin desconocer los aspectos negativos que les genera el uso de las aplicaciones como por ejemplo la ansiedad de que la otra persona responda, mayormente hacen mención a las facilidades, en términos racionales, que les provee para su sexualidad, en un sentido amplio del término. Dentro de las mismas se encuentran: la comodidad, accesibilidad, la maximización del uso del tiempo y la geolocalización. Estos atributos se corren de guiones románticos y se pondera una sexualización en términos de costobeneficio, los cuales se vinculan con las características propias de la modernidad tardía signada por la escasez de tiempo libre para sociabilizar por fuera del ámbito laboral y 
por el uso de las aplicaciones durante el horario de trabajo. Otras características son la fugacidad, la pérdida del poder adquisitivo de los sectores medios, la inmediatez, los miedos vinculados a la violencia y la inseguridad.

En relación con la comodidad, la accesibilidad y la maximización del uso del tiempo, se indica que las búsquedas virtuales permiten relacionarse de manera más rápida y sencilla. Se entra en contacto con solo bajar la aplicación y se puede buscar a una persona a cualquier hora y lugar, incluso mientras se realiza otra actividad. En el contexto de la Ciudad de México quienes trabajan en relación de dependencia en oficinas públicas o privadas mencionan en las distintas entrevistas que sus jornadas laborales comúnmente rondan entre las diez y doce horas, y en algunos casos más. Esto tiene lugar en un marco de flexibilización del mercado de trabajo y de pérdida de derechos laborales. ${ }^{12}$ Según datos de la Organización para la Cooperación y el Desarrollo Económico (OCDE, 2016), México es el país junto con Costa Rica donde las personas trabajan más horas al año. ${ }^{13}$ Esto conlleva, según los/as propios/as entrevistados/as, que el tiempo para sociabilizar en espacios cara a cara se vuelva verdaderamente exiguo y que mientras trabajan utilicen las aplicaciones. Es decir, el esparcimiento a través de redes sociales se da en espacios laborales, lo cual va en contracorriente a las lógicas más productivistas del capitalismo.

A la falta de tiempo y dinero para sociabilizar cara a cara, se le suma la complejidad de las distancias y el tráfico que posee esta ciudad, tal como desarrollaré en breve. Juana (36 años, soltera y sin hijos/as, Ciudad de México) refiere que "El tema de chatear es cómodo porque si estás todo el día en la oficina puedes ir conociendo a alguien. Puedes estar haciendo una actividad y al mismo tiempo hablando con la otra persona. Eso está bueno. Puedes estar todo el día en la oficina y en un viaje y vas conociendo en paralelo a la persona".

Juan (44 años, soltero y sin hijos/as, Ciudad de Buenos Aires) también hace referencia a la comodidad: "La uso cuando tengo tiempo libre, por ejemplo, estoy terminando de tomar un café y estoy solo, tranquilo en mi casa y disparo". Con el verbo disparar refiere a la acción de marcar un perfil con una cruz o un corazón, es decir, marcar agrado o desagrado. "Me gusta, no me gusta. Me gusta, no me gusta. Me gusta, no me gusta. Cruz, corazón. Cruz, corazón, cruz, corazón". Tinder le permite desde la comodidad de su hogar buscar vínculos eróticos y/o afectivos, de manera inmediata. Asimismo, en su descripción condensa la lógica fugaz e inmediata con la cual se sociabiliza en la actualidad (Maffesoli, 2009).

Si bien el hecho de tener un Smartphone, con las características necesarias para poder tener descargadas las distintas aplicaciones que se utilizan diariamente, implica un gasto, este no es problematizado por los/as entrevistados/as como tal. Por el contrario, el hecho de tener un celular con ciertos estándares tecnológicos está naturalizado como un gasto necesario. Para los/as entrevistados/as de sectores medios aquí relevados, de ambas ciudades, el teléfono es visto como un objeto-prótesis de su propia existencia que les habilita a tener aplicaciones desde las cuales sociabilizar de manera gratuita. ${ }^{14}$ Esto lo contraponen al gasto que conlleva salir a un bar o a una discoteca, que son los ámbitos cara a cara donde más suelen ir para vincularse eróticamente con otros.

Los varones hacen especial énfasis en el tema del gasto ya que son quienes pagan principalmente las citas, a modo de cortejo. Para ellos el hecho de tener acercamientos previos a través de medios virtuales, como son conversaciones por WhatsApp o llamadas telefónicas, con una potencial cita magnifica la posibilidad de que haya un incremento de energía emocional (Collins, 2009) entre ambos en el encuentro cara a cara, y que el gasto que deben llevar a cabo durante la cita sea visto como
12. El 30 de noviembre del 2012 se reformó la Ley Federal del Trabajo en México. Las disposiciones que fueron adicionadas y reformadas implican una pérdida de derechos laborales, entre las mismas se encuentran: flexibilización de la contratación de personal (contrato de prueba, de capacitación inicial, de temporada, etc.); individualización de la relación salarial, con mecanismos que vinculan la retribución a la productividad y el desempeño individual de los trabajadores; descentralización de la negociación colectiva; reducción de los costos del despido; eliminación de la antigüedad, como un criterio en la movilidad de los trabajadores; flexibilización de la jornada de trabajo; reducción de las sanciones a la empresa en caso de que se demuestre el despidos injustificado (excepto salarios caídos); entre otros. (Belmont Cortés, 2014; Sanchez Castañeda, 2014)

13. Datos obtenidos del documento "Average annual hours actually worked per worker"

realizado por Organización para la Cooperación y el Desarrollo Económico (2016). Recuperado de: <http://stats.oecd.org/Index aspx?DatasetCode=ANHRS $>$.

14. No obstante, un rasgo que tienen en común todas las aplicaciones de citas es que existe la opción de pagar para acceder a una cuenta premium que habilita otras funciones que, en algunos casos, mejoran la cantidad de personas que se pueden conocer y, en otros, hacen más visible al perfil del usuario/a. 
15. El Estado de México es un estado que rodea a la Ciudad de México. Las 16 delegaciones pertenecientes a la Ciudad de México y 27
municipios del Estado de México conforman la Zona Metropolitana de la Ciudad de México (ZMCM). una "inversión". Para Collins, la energía emocional implica un estado anímico que perdura en el individuo tras haber compartido con otros, colectivamente, un mismo estado emocional. El aumento o disminución de la misma dependerá de que haya consonancia entre las partes, lo cual se puede observar en los gestos comunicativos y ritmos corporales y comunicacionales. La energía emocional, para Collins, se acumula en recuerdos, ideas, creencias y símbolos que se recicla en redes de conversaciones, diálogos anteriores y en cadenas de rituales de interacción que sucedan posteriormente (Rizo García, 2015: 56).

Otro punto que los/as usuarios/as vinculan a la comodidad que ofrece Tinder es su opción de geolocalización. La aplicación, en su opción premium, habilita vínculos a nivel global, los/as usuarios/as puedan relacionarse con personas de cualquier parte del mundo. Por su parte, la opción gratuita, que es la utilizada por las mujeres y los varones entrevistadas/os, permite conocer por default a personas que se encuentren a 100 kilómetros a la redonda. No obstante, los/as entrevistados/as de la Ciudad de México, quienes usan la opción gratuita de Tinder, circunscriben sus búsquedas a un rango reducido de kilómetros debido al tráfico y a las largas distancias que delinean la ciudad. Las distancias deseables que colocan en sus búsquedas es mucho menor a la que eligen los/as entrevistados/as que viven en la Ciudad de Buenos Aires. Los/ as argentinos/as no le presentan una especial atención al hecho de seleccionar la distancia de búsqueda, ya que suelen dejar la que viene por default en la app. Aunque luego si la persona se encuentra demasiado lejos no la seleccionen. Los/as residentes de la Ciudad de México, en cambio, eligen activamente dentro de un rango máximo de entre 10 y 20 kilómetros.

Si bien el tráfico es la explicación a la cual refieren más frecuentemente los/as mexicanos/as que residen en la Ciudad de México para precisar el por qué eligen rangos de búsqueda reducidos, también hacen mención a la seguridad y esbozan un criterio de clase. El Estado de México ${ }^{15}$, donde vive una amplia mayoría de sectores populares, es considerado por quienes habitan en la capital mexicana como un lugar peligroso. Dicho de otro modo geolocalizar es uno de los medios que utilizan los/as usuarios/ as para ubicar sus búsquedas en coordenadas espaciales donde viven personas de sectores sociales similares. Cuando le consulté a Guadalupe dónde ubicaba su radio de búsqueda me respondió: "15 kilómetros así solo llega hasta el norte de la ciudad, pero no al Estado de México (...) Por un poco de miedo y reserva (risas). La periferia de la Ciudad es el Estado de México y son zonas muy peligrosas... Eso me da un poco de seguridad" (Guadalupe, 33 años, soltera sin hijos/as, Ciudad de México).

También en la Ciudad de Buenos Aires las personas entrevistadas eligen vincularse erótica y/o afectivamente con personas de sus mismos sectores sociales (homogamia). Tanto en una ciudad como en la otra, la educación es un aspecto fundamental, aunque se observa una mayor importancia en torno a la misma en las mujeres y varones que residen en la Ciudad de México y en las mujeres que viven en la Ciudad de Buenos Aires. Si bien los criterios de selección sobre los perfiles exceden el objetivo de este artículo, es importante señalar que una especificidad propia de la Ciudad de México se vincula con la importancia que se le otorga al momento de entablar relaciones de pareja al hecho de conocer el origen familiar de la otra persona. Este criterio opera como un indicador sobre los valores y los aspectos morales del sujeto (Rodríguez, 2016: 38). En cambio, en el caso de la Ciudad de Buenos Aires, el origen familiar actúa garantizando similitudes en términos de origen de clase, lo cual proporciona a las personas, una base de afinidades inmediatas basadas en el entendimiento y la comprensión mutua respecto a los gustos y a los estilos de vida (Rodríguez, 2016: 27).

En relación con la seguridad, las entrevistadas que residen en la Ciudad de Buenos Aires y de la Ciudad de México dicen experimentar situaciones que consideran 
abusivas, por ejemplo, que un varón en cuanto hace match les proponga tener sexo o les envíe fotografías de sus genitales. No obstante, Tinder les brinda, según sus propios testimonios, iguales o más seguridades que conocer a alguien cara a cara. La aplicación se encuentra vinculada a Facebook, lo cual les permite saber si poseen contactos en común y obtener información a partir de observar los perfiles -allí se pueden ver fotos, qué tipos de comentarios hace, cuáles son sus gustos-. Además, que previo al encuentro cara a cara, las personas tienen instancias intermedias de vinculación como por ejemplo chats, llamadas telefónicas. Para las personas que viven en la Ciudad de México estas estrategias de cuidado aparecen exacerbadas y son empleadas tanto por varones como por mujeres. Ambos hablan del miedo de ser secuestradas o robados y en el caso específico de las mujeres aparece con más frecuencia el miedo a la violación, en el marco de una sociedad espoleada por problemas graves de narcotráfico, secuestros, feminicidios, desapariciones forzadas y violencias de todo tipo. Es decir, la aplicación les ofrece a las mujeres, por sobre los varones, más información y conocimiento sobre una persona previo al encuentro cara a cara. Lo virtual para ellas vuelve a sus futuros compañeros varones menos anónimos que si el encuentro fuese directamente en discotecas y bares.

Una de las entrevistadas que vive en la Ciudad de México, Teresa (40 años, soltera sin hijos/as), explica que ella no suele tomar medidas de seguridad específicas al momento de tener una cita. Su estrategia de cuidado se afianza en tener conversaciones previas con sus potenciales candidatos. Considera que si hay intereses y gustos en común y un sentido del humor afín están dadas las condiciones para tener un encuentro amoroso. Esta actitud más bien despreocupada, sin embargo, es vista negativamente por su entorno. "Teresa: Está mal visto. Yo hablaba con varios compañeros de la oficina que tienen el problema del tiempo y yo les digo, úsenla. A varias compañeras le platicaba de esto y se reían. Cuando hablaba de esto con mis amigas les parecía raro. Ellas están todas casadas" (Teresa, 40 años, Ciudad de México).

Para los/as entrevistados/as que residen en la Ciudad de Buenos Aires el tema de la seguridad al momento de tener una cita con alguien que conocen por la aplicación es un aspecto que se evalúa, pero se toma en cuenta en menor medida respecto de sus pares mexicanos/as. A diferencia del caso de los varones mexicanos que residen en la Ciudad de México, no aparecen en sus relatos miedo a los secuestros, a las desapariciones o al narcotráfico a causa del uso de las aplicaciones. Para Leonardo son más seguras las aplicaciones como Tinder porque están relacionados a Facebook, "lo cual nos permite saber si tenemos contactos en común". Asimismo, desde Facebook se puede mirar el perfil de la otra persona y desde los buscadores de Internet es posible indagar sobre ella.

Si bien las entrevistadas que residen en la Ciudad de Buenos Aires se sienten más seguras en la utilización de Tinder, respecto a las que viven en la Ciudad de México, son igualmente precavidas sobre posibles situaciones de violencia de género que pudieran llegar a vivir en un encuentro cara a cara con una persona que conocen por Tinder. Le avisan a alguien de confianza que tendrán una cita y se reúnen en lugares cerca de su casa. Están atentas, al igual que sus congéneres mexicanas, ante los perfiles falsos, miran las fotografías y se niegan a tener citas cara a cara con quienes le parecen poco confiables o incoherentes, por ejemplo, un varón que supuestamente tiene hijos/as y nunca haga referencia a ellos/as. Este miedo a los perfiles falsos se exacerba en el caso de una de las entrevistadas que reside en la Ciudad de México, Guadalupe (33 años, soltera sin hijos/as). Ella le solicita el número de celular a la otra persona para cotejar si hay una cuenta en Facebook vinculada.

Respecto a la maximización del tiempo, en un contexto donde hay escasez de tiempo libre, las personas entrevistadas refieren a que usan las apps en sus tiempos "muertos": 
16. Explica Esteinou (2010) que en los años sesenta, en México, la tasa global de fecundidad fue de 7.2 hijos por mujer y para el año 2000 fue de 2.5 (Mier y Terán y Partida, 2001. Flores (ruz). En cambio para el contexto argentino para los años esenta es de 3.1 hijos por mujer y para el año 2000 es de 2.4 (Flores Cruz, s/f). Si bien los/as entrevistados/as que residen en la Ciudad de México poseen un número similar de hermanos/as respecto al caso argentino, tienen una mayor cantidad de tino, tienen una mayor cantidad de Esto amplía el número de la familia. 17. Los actantes son personajes o fuerzas impersonales que habilitan o no acciones y relaciones del actor (Meccia, 2012).

18. Observo que es en la Ciudad de México donde aparecen más perfiles de personas extranjeras residiendo de vacaciones en la ciudad. Esto se debe en parte a que dicha ciudad es debe en parte a que dicha ciudad es
según la Organización Mundial de Turismo (2016) el octavo país más visitado por turistas en el mundo y

el primero en América Latina y que gran caudal de ese turismo pasa

por la Ciudad de México (Secretaría de Turismo de México, 2010) cuando están aburridos/as en el trabajo, a la noche antes de irse a dormir, cuando terminan de comer o mientras realizan otra actividad como mirar la televisión. Es en estos momentos cuando sociabilizan de forma múltiple y en cantidad, y chatean en simultáneo con varias personas.

Ernestina (43 años, divorciada, Ciudad de Buenos Aires), tiene dos hijos y es quien se ocupa principalmente del cuidado de los mismos, y Tinder, en ese marco, devino un medio cómodo y acorde a sus tiempos para poder sociabilizar erótica y/o afectivamente con varones. La entrevistada dice ser cuidadosa respecto al tiempo que le dedica al uso de la aplicación. Dice, "uso Tinder solo para cuando tengo un tiempito y ver qué onda. Pero no es que lo tengo articulado $100 \%$ a la vida. Y me protejo mucho de evadirme de mi misma". El tiempo en las sociedades capitalistas actuales es un valor fundamental y debe ser utilizado de manera productiva (Thompson, 1979). Cuando Ernestina se refiere a que la usa cuando tiene un "tiempito" se presenta como una persona ocupada y productiva en otros ámbitos de su vida. A su vez, cuando ella indica que se protege de evadirse a sí misma, aparece el efecto negativo que conlleva el uso de las aplicaciones como son las ansiedades vinculadas al hecho de que la otra persona responda o que el perfil reciba suficientes likes, lo cual aumenta la autoestima de los/as usuarios/as. Ernestina se muestra como una agente reflexiva sobre su uso y se cuida de no estar al pendiente de la sociabilización por los medios virtuales que están habilitados a toda hora y todos los días del año. El hecho de no estar al pendiente de las aplicaciones y de usarlas en el tiempo libre, tanto en varones como en mujeres, se vincula a un contexto de individualización donde los sujetos viven sus acciones como productos de su propia reflexividad, responsabilidad y autonomía individual y al miedo de percibirse y ser percibidos como "desesperados/as" por otros.

Estas premisas de maximización del uso del tiempo, la comodidad y la accesibilidad que ofrecen las aplicaciones de citas se observan también en el contexto de la Ciudad de México, aunque de manera más pronunciada. Como se explicó anteriormente los/ as entrevistados/as que residen en la Ciudad de México son quienes hacen referencia durante las entrevistas a que sus jornadas laborales limitan las posibilidades materiales para que puedan sociabilizar en espacios cara a cara. Tinder es así un medio elegido como modo óptimo, en términos racionales, de conocer personas, porque se visualizan una multiplicidad de perfiles de manera fugaz e inmediata.

Asimismo, en el contexto de la Ciudad de México, a diferencia del de la Ciudad de Buenos Aires, la familia aparece como un actante ${ }^{16}$ que insume al igual que el trabajo una gran cantidad de tiempo. Las familias son más amplias ${ }^{17}$ y aparece que los/as entrevistados/as destinan una gran cantidad de tiempo a eventos familiares. Explica Isabel, "Siempre hay un evento familiar, siempre hay algo. Interviene consumiendo tiempo. Nosotros somos mi mamá, mi papá y mi hermano. Pero mi papá tiene siete hermanos y mi mamá cinco. Eso genera muchos eventos familiares" (Isabel, 35 años, soltera sin hijos/as, Ciudad de México).

Por último, en relación con la geolocalización, además de permitir especificar un rango de búsqueda, Tinder les permite a las personas entrevistadas sociabilizar cuando se encuentran en otras ciudades. Los/as entrevistados/as de ambos países hacen mención a su utilización cuando están de vacaciones en otros lugares. ${ }^{18}$ En el próximo apartado me centró en ver cómo opera este aspecto en el orden de las expectativas de los/as usuarios/as de Tinder. 


\section{Motivaciones y expectativas en el uso}

Existen una multiplicidad de motivaciones por parte de los/as usuarios/as al momento de usar las aplicaciones. Algunas se vinculan con la diversión de observar los perfiles de otras personas sin necesariamente indicar preferencia por alguno o como modo de autoerotización. Otras se relacionan con búsquedas de encuentros meramente sexuales, de pareja y las hay también, de tener hijos/as.

En este apartado me detendré en tres tipos de expectativas: las afectivas, vinculadas al deseo de constitución de pareja y de tener hijos/as, en aquellas que no se vinculan a ningún tipo de expectativa erótica y/o afectiva; y por último, en las que se asocian a las expectativas eróticas de tipo sexual.

Durante las entrevistas los/as usuarios/as explican que, por un lado, el uso de la aplicación no se relaciona necesariamente con la búsqueda de pareja, pero que, a su vez, la posibilidad de entablar un vínculo de ese tipo es un horizonte de sentido deseable por ellos/as. Es decir, el amor romántico en relación con los postulados heteronormativo ${ }^{19}$ de cohabitación y fidelidad aparece, aunque bien sea a nivel aspiracional, como un proyecto o ideal en las/os heterosexuales entrevistadas/os. En términos de Ben e Insausti (2017) el modelo de pareja deseable que predomina es el monógamo serial, a partir del cual si bien pueden existir relaciones o encuentros sexuales por fuera de la pareja, esta aparece como el ámbito privilegiado en el que deben concentrarse la sexualidad y el afecto (Ben e Insausti, 2017: 43).

Existen diferencias en torno a la adecuación a este ideario entre los/as entrevistados/ as que viven en ambas ciudades y según el género de los actores. En las mujeres esta aspiración aparece de forma más pronunciada, aunque con resistencias. La cohabitación es una apuesta que genera reticencias en las mujeres divorciadas o separadas, en cambio en quienes nunca convivieron la aprecian positivamente. Asimismo, las mujeres que residen en la Ciudad de Buenos Aires si bien apuestan a la búsqueda del "amor", transitan el uso de la aplicación teniendo, con más frecuencia que las que habitan en la Ciudad de México, diferentes citas con quienes se vinculan sexualmente sin ningún otro tipo de compromiso. En cambio, las que viven en la Ciudad de México según sus relatos, salvo en el caso de Teresa, comentan que tienen trayectorias eróticas menos heterogéneas que las argentinas.

Por su parte, los varones que residen en la capital mexicana poseen trayectorias eróticas, a partir de este medio, más reducidas que sus pares argentinos. Por ejemplo, en el caso de uno de los entrevistados nunca logró concretar una cita por Tinder. El uso de la aplicación tiene un efecto negativo en su autoestima, le genera inseguridad y lo hace dudar sobre su capital erótico (Hakim, 2010). En los demás casos refieren a que conocieron solo a dos o tres mujeres por esta vía, pero no hubo, en los primeros encuentros, relaciones sexuales. Asimismo, al momento de la entrevista dos de los entrevistados que residían en la Ciudad de México estaban comenzando a vincularse con mujeres que conocieron a partir de Tinder y que consideraban que podrían devenir en relaciones monógamas estables. Por ejemplo, en el caso de Lázaro ${ }^{20}$ (38 años, de novio y sin hijos/as, Ciudad de México), quien convivía y estaba en pareja con una mujer que había conocido en Tinder, antes de salir con ella había tenido solo una cita con una mujer que había conocido a través de la aplicación.

En relación con la maternidad o paternidad, en todos/as los/as entrevistados/as que no tienen hijos/as, el ser padres o madres en el marco de una relación de pareja estable también se visualiza como un horizonte de sentido, bajo la égida de la matriz romántica y heteronormativa prevaleciente (Esteban, 2011). Si bien este deseo reproductivo se presenta en ambos géneros, hay diferencias en la forma de vehiculizarlo
19. En el amor romántico la conexión entre el amor y la atracción sexual, propias del amor pasión, se perpetúan en los idearios románticos. Otros elementos que configuran al amor romántico son el amor agápico que implica la entrega total al sujeto amado (Illouz, 2009), la intimidad y la representación de que el lazo amoroso debe ser el vínculo más importante en los sujetos. En relación con los postulados heteronormativos el amor romántico se encarga en la cohabitación, la monogamia y la procreación (Herrera Gómez, 2012; Esteban, 2011).

20. Aparece en este análisis el caso de un varón que estaba en pareja con una mujer que había conocido por Tinder. Al momento de pautar la entrevista entendí que estaba soltero, pero durante el desarrollo de la misma me indicó que estaba en pareja. No descarté la entrevista en tanto brinda información rica sobre el uso que realizó de la aplicación y sus expectativas de búsqueda, lo cual permite enriquecer el análisis. 
entre mujeres y varones. Estas divergencias provienen de la propia construcción de género femenina (de Lauretis, 1996), en la cual la maternidad es una forma de realización y reconocimiento en tanto lo femenino está vinculado a la idea de cuidado y afectividad (Burin, 2003). Mujeres que pospusieron la maternidad, ya sea en pos de su carrera profesional o porque no encontraron "al candidato adecuado" y quieren tener hijos/as, al acercarse al final del "reloj biológico" (Dever y Saugeres, 2004; Klinenberg, 2012) se informan $y / u$ optan por otros medios mediados por soluciones de mercado como es la reproducción biotecnológica (congelamiento de óvulos e inseminación). Asimismo, en el caso de una de las mujeres que reside en la Ciudad de México la aplicación es un medio a partir del cual logró quedar embarazada.

Es decir, aparecen en los relatos de las mujeres una agencia en pos de alcanzar su deseo materno, más allá de una búsqueda afectiva de relación de pareja. En dos de las entrevistadas esto es vehiculizado de manera diferenciada, Ángeles (40 años, soltera sin hijos/as, Ciudad de Buenos Aires) optó por medios de reproducción biotecnológica y Mónica (36 años, soltera, Ciudad de México) lo logró a través de la aplicación Tinder. Al momento de la entrevista, Mónica hacía poco tiempo que había dejado de utilizar Tinder debido a que se había enterado de que estaba embarazada. Ella comenzó a utilizar la aplicación al mismo tiempo que un grupo de amigas, todas solteras. $\mathrm{Me}$ explica que ella siempre tuvo facilidad para conocer personas en ámbitos cara a cara, como en el trabajo, la universidad y en fiestas. Como forma de diversión y por ser un tema de conversación con sus amigas comenzó a usar Tinder. Como dice ella "estaba en el chisme de querer saber si había alguien conocido ahí".

Cuando hacía match con un varón esperaba, dentro de los cánones románticos, que el varón le comenzara a hablar. Las conversaciones no pasaban de chats. Solo con uno inició una relación de dos meses marcada por escasos encuentros. En una de los mismos ella tuvo relaciones sexuales con su cita. Él no se puso preservativo y ella tampoco le pidió que lo haga. Tal como ella refiere "no nos cuidamos ninguno de los dos". Mónica apenas se dio cuenta que estaba embarazada lo habló con la persona con quien salía. Según me explica, ella no se sentía enamorada de él y no esperaba que él se hiciera cargo de la situación, lo cual fue lo que sucedió. No operaba en ella un discurso romántico y heteronormativo de tener hijos/as a través de un vínculo de pareja, sino que su interés estaba centrado en ser madre.

Si bien Mónica no se bajó la aplicación con la finalidad premeditada de conocer a alguien para quedar embarazada, le fue útil como medio para alcanzar su deseo materno de manera sencilla y sin que medie el dinero, como es en el caso de Ángeles que tuvo que pagar por el tratamiento de inseminación artificial.

En el caso de los varones que no tuvieron hijos/as, ellos también usan la aplicación como medio para encontrar una pareja con quienes, quizás, tenerlos/as. No obstante, este tipo de búsqueda afectiva -sobre todo en los más jóvenes- es menos frecuente como así también menos urgente en relación con las mujeres. Esto se debe a que su tiempo biológico de procreación sin que intervengan medios de reproducción biotecnológica es más amplio y prevalece, a diferencia de lo que sucede con las mujeres, una mayor aceptación social y posibilidad de entablar pareja con mujeres más jóvenes (Torrado, 2007).

Dentro de una estructura heterosexista desigual de relaciones entre los géneros la pérdida del look age (parecer de una edad) joven (Featherstone y Hepworth, 1991), entendida como parte del capital erótico de los sujetos (Hakim, 2010), es percibida más negativamente sobre las mujeres que sobre los varones. Los varones consideran que una mujer sin hijos/as cercana a los cuarenta años de edad y que busca vínculos eróticos y/o afectivos está "desesperada" o apresurada por encontrar un varón con 
quien tenerlos. Es por ello que los/as entrevistados/as tienden a colocar en sus rangos etarios de búsqueda a mujeres más jóvenes que ellos -esta diferencia se acentúa según cuantos más años ellos tengan-. Esto sucede tanto en el contexto de la Ciudad de México como en el de la Ciudad de Buenos Aires.

Dentro de la variedad de expectativas al momento de elegir usar Tinder se encuentran aquellas que trascienden el formato para el cual fue creada la aplicación. Si bien Tinder ha sido inventada para la generación de citas, si lo analizamos desde de Certeau (1996), vemos que los sujetos se reapropian y generan una producción secundaria que excede el propósito para el cual fue creada la app. En las entrevistas Tinder, en el marco de un mundo global donde hay una amplia circulación de personas, aparece como un modo a partir del cual personas desconocidas y que se encuentran fuera de su lugar de residencia pueden contactarse. Por ejemplo, las personas cuando se encuentran de vacaciones la emplean para divertirse al mirar los perfiles de otros o como medio de consulta sobre las atracciones que ofrece un destino turístico. Hay personas que escriben en su perfil que buscan conocer gente con quien salir a recorrer un lugar en el cual se encuentran de vacaciones. Juana (36 años, soltera sin hijos/as, Ciudad de México) comenta que ella hizo match con un varón argentino que recién acababa de llegar a vivir a Ciudad de México. A medida que comenzaron a hablar se dieron cuenta de que no había energía emocional (Collins, 2009) como para un encuentro de tipo erótico, pero sí para juntarse a conversar y compartir una salida, una tarde de fin de semana. Tinder le fue útil a ese varón como un medio de adaptación a la nueva ciudad donde había ido a residir buscando nuevos horizontes laborales, pudo contactarse con personas mexicanas y conocer la ciudad a donde se había mudado.

A partir de mis observaciones a perfiles y por comentarios de los/as entrevistados/ as, considero que la opción de geolocalización facilita la sociabilidad entre personas de distintas ciudades y países, aunque con habitus de clase afines.

Los perfiles de las mujeres y los varones extranjeros/as que se encuentran por trabajo o vacaciones en la Ciudad de México o en la Ciudad de Buenos Aires indican su nacionalidad, qué están buscando -salir a conocer la ciudad con algún local o tener encuentros sexuales-, qué se encuentran haciendo en la ciudad y, en caso de que provengan de países no hispanos hablantes, qué idiomas hablan. Una de las entrevistadas mexicanas, Teresa (40 años, soltera sin hijos/as), refiere a la descripción del perfil de un extranjero el cual captó su atención y con quien tuvo un romance de tres semanas mientras él estaba de vacaciones en la ciudad de la siguiente manera. "Me pareció muy franco que en su perfil dijese que estaba viajando y que quería conocer gente que quisiera compartir parte de su vida para enseñarle español a un holandés. Es eso: compartir. Eso es distinto a alguien diga quiero sexo. Guey, ok. Pero ni siquiera sé si tengamos química y tú ya estás poniendo esta regla".

En relación con las motivaciones eróticas de tipo sexual, tanto en la Ciudad de México como en la de Buenos Aires, las mujeres dicen que les generan rechazo aquellos perfiles con menciones sexuales explícitas, por ejemplo "Busco sexo casual" (Perfil observado en Tinder de un varón, 40 años, Ciudad de Buenos Aires). Ellas indican que prefieren aquellos con una descripción creativa o que esté formulada dentro de guiones de tipo romántico. No obstante, tampoco son deseados aquellos perfiles que parecen "desesperados" como por ejemplo "Busco a una mujer que me acompañe en esta vida" (Perfil observado en Tinder de un varón, 44 años, Ciudad de Buenos Aires)

Por su parte los varones de ambos países dan mayormente like a las mujeres que indican que son nacidas en países caribeños como Colombia, Venezuela o Cuba. Consideran, desde una mirada racista y cosificante, que estas feminidades poseen perse un alto capital erótico (Hakim, 2010). Cuando les consultó por qué les parecen 
21. Sugar daddy es una expresión que se emplea para referirse a un varón que ofrece dinero o regalos una persona más joven a cambio de compañía o favores sexuales. atractivos los perfiles de esas mujeres apelan a que sus cuerpos son más curvilíneos o las asocian a una hipersexualización por el simple hecho de haber nacido en lugares con clima caluroso.

Con uno de los entrevistados, Carlos (41 años, Ciudad de México) tindereamos juntos, es decir que él usó Tinder durante la entrevista y a medida que iba observando los perfiles, elegía y me explicaba el porqué de cada elección. Él seleccionó, al igual que otros entrevistados que viven en la capital mexicana y en la argentina, a mujeres que sugerían de manera implícita que buscaba tener relaciones sexuales -no observé ningún perfil femenino que lo dijera explícitamente, como sí lo hacían los varones-. Según ellos, si bien no creían posible que esas mujeres voluptuosas y sexys vayan a darles, de manera recíproca, like, marcaban igualmente su deseo. En el caso de Carlos, por ejemplo, marcó con un corazón el perfil de una mujer que sugería que le interesaba recibir dinero a cambio de dar compañía. El perfil decía “¿Quién se anima a ser un SugarDaddy? ",21 (Perfil observado en Tinder de mujer, 30 años, Ciudad de México) y estaba acompañado de fotografías sensuales donde ella vestía con poca ropa y en posiciones en las cuales "quebraba la cadera" o estaba de espaldas contra una pared. A él le parecía excitante la posibilidad, aunque mediara el dinero, de estar con esa mujer que en su perfil se mostraba sexual y dispuesta a un vínculo por fuera del romanticismo.

Los varones de ambos países eligen perfiles de mujeres que posean fotos en las cuales ellas detentan alto capital erótico, a saber, aquellas donde están en bikini en playas y/o visten escotes. No obstante, los varones y mujeres aquí abordados, de sectores medios, hacen énfasis en que prefieren a personas cuya hexis corporal esté alejada de los sectores populares. Fotografías que les generan interés son aquellas en las cuales las personas se encuentran en destinos turísticos nacionales o extranjeros-como por ejemplo la Torre Eiffel- o en restaurantes o bares que posean una decoración que denote un cierto poder adquisitivo. Además de estos escenarios, para el caso de la Ciudad de México son frecuentes las fotografías en el ambiente de trabajo. Esta es una forma explícita de mostrar que trabajan y que poseen cierto nivel adquisitivo. En los perfiles de personas que residen en la Ciudad de Buenos Aires aparecen en más cantidad imágenes en destinos extranjeros y/o que poseen como escenario a los deportes náuticos. Las mismas permiten asociar de manera implícita la pertenencia a una clase.

\section{La agencia femenina}

La modernidad tardía, en la cual se enmarca la segunda transición demográfica, está signada tanto para el contexto mexicano como para el argentino, por una mayor aceptación social de la sexualidad, la reivindicación de la autonomía individual, un mayor control de las mujeres sobre la reproducción, un avance en legislación y posicionamiento por parte de ellas y por colectivos de la diversidad sexual, una apuesta de las mujeres a priorizar sus carreras y actividades personales por sobre el mandato de la familia y la maternidad, como así también una disminución en el número de nacimientos (Ariño, 2007; Jelin, 1989; Mazzeo, 2010; Torrado, 2007).

Estadísticamente se observa que la tasa global de fecundidad (hijas/os por mujeres) en la Ciudad de Buenos Aires ha decrecido (para 1990 era de de 2,08 mientras que para el año 2015 fue de 1,78). Para el año 2015, la cúspide de fecundidad femenina se encuentra dilatada, compartida por los grupos $25-29$ y 30-34, y su punto más alto se ubica entre los 30 y 34 años. Según la Encuesta Anual de Hogares del año 2015, el 20\% de las mujeres que están finalizando su período fértil -que tienen entre 40 y 49- no 
han sido madres. En el caso de la Ciudad de México, la tasa global de fecundidad también está en decrecimiento (en el año 1999 era de dos hijos/as por mujer y para el año 2009 fue de $1,8 \mathrm{hijos} / \mathrm{as}$ ) y su estructura de fecundidad posee una cúspide dilatada compartida por los grupos de mujeres de 20 a 24 y de 25 a 30 (Instituto Nacional de Estadística y Geografía de México, Censos de Población 2000 y 2010).

En este contexto de mayor autonomía femenina en relación con la creciente "mercantilización de la vida íntima" (Elizalde y Felitti, 2015; Hakim, 2010; Hochschild, 1983; Illouz, 2007, 2012) propia del capitalismo posmoderno, las mujeres aparecen como activas consumidoras del mercado sexual y afectivo. En una entrevista en FM Latina 101.1, Argentina, el director de Tinder para América Latina marca una amplia presencia femenina en el uso de la aplicación Tinder, el $48 \%$ de las usuarias son mujeres y el $52 \%$ hombres (Iorio, 2016).

Las características propias de Tinder: el anonimato, el hecho de observar sin ser vistos como así también la posibilidad de cerrar y volver a abrir el perfil de forma rápida, les permiten a las mujeres posicionarse en mayor medida, a diferencia de los ámbitos cara a cara, como agentes activos en las búsquedas. Para que las personas puedan comenzar a vincularse por Tinder cada una por su parte debe marcar con un corazón el perfil que observa. Esto lleva a que las mujeres, si quieren entrar en contacto con otros, deban indicar más allá del deseo masculino agrado o desagrado. No obstante, si bien vemos un avance de las mujeres como agentes que marcan o no interés, tanto en la Ciudad de Buenos Aires como en la Ciudad de México luego de que hicieron match con un varón, las mujeres esperan que sean ellos quienes les escriban. Se reproduce una forma de cortejo, más allá del contenido que la sustenta, basada en la idea de caballerosidad del discurso del amor cortés, entendida como la adulación y adoración de la mujer como claves de conquista (Tin, 2012).

En relación con las representaciones que posee el entorno de las usuarias sobre el hecho de que ellas usen y tengan citas con varones que conocen por Tinder, hay diferencias en ambos contextos. En la Ciudad de Buenos Aires se aprecia una mayor apertura. Los familiares son actantes que aparecen en las entrevistas facilitándoles a las mujeres información o presentándoles potenciales candidatos para que generen vínculos de pareja. Es decir, hay una mayor permeabilidad a hablar y a aconsejarlas para que establezcan relaciones, pero principalmente de pareja y no de otro tipo como podría ser sexo casual.

En cambio, en la Ciudad de México la búsqueda de vínculos eróticos y/o afectivos a partir de medios virtuales es un tema más acallado y genera socialmente más recelo, aunque haya hoy en día una mayor aceptación. Juana explica "Cuando comencé a usar las aplicaciones y le conté a mis hermanos mayores era de 'Noooo'. Sentían que estaba de prostituta, anunciándome en un periódico. Era así de 'no manches'. Tú estás guapa, puedes conocer a alguien por otro lado. Ahora ya es más común y hay historias de éxito de personas que se conocieron por las aplicaciones" (Juana, 36 años, Ciudad de México).

Asimismo, este recelo lo experimenté en primera persona al momento de comenzar a hacer trabajo de campo en la Ciudad de México. Para establecer los primeros contactos de entrevistas les solicité ayuda a personas conocidas. Lo primero que me respondían era que el tema que yo quería abordar era muy íntimo y que les daba pena $a^{22}$ preguntar. Por ejemplo, un amigo argentino que vive y trabaja en la Ciudad de México en el área de marketing de una empresa multinacional cuando le pregunté si podía hablar con gente de su oficina me dijo "No conviene pedir ese tipo de favores. Además, casi no se habla en la oficina de esas cosas, son súper tímidos. En la Argentina pena” a la emoción de la vergüenza. hablábamos mucho más. Siento que acá son más conservadores". 
Gracias al entorno de colegas y amigos/as mexicanos/as pude, paulatinamente, conseguir contactos para entrevistas, especialmente de amigas de amigas. No obstante, a los varones mexicanos fue más difícil entrevistarlos y la duración de las charlas tendió a ser más bien corta. Encuentro en los mexicanos que viven en la Ciudad de México, a diferencia de lo que sucede con los argentinos que residen en la Ciudad de Buenos Aires, un mayor ocultamiento y reserva sobre sus sentires y experiencias.

Hipotetizo que el silencio de los mexicanos que residen en la Ciudad de México y el hablar en demasía de los argentinos que viven en la Ciudad de Buenos Aires pueden ser leídos como dos formas que poseen los entrevistados para reafianzar su masculinidad hegemónica (Connell, 1995). En estos últimos aparece el relato, cargado de detalles eróticos, como un medio de denotar su virilidad y heterosexualidad, a partir de contarme sus múltiples anécdotas sexuales y "aventuras". Por su parte, los residentes de la Ciudad de México reafirman su masculinidad a partir del ocultamiento y una mayor reserva sobre el hecho de expresar sus sentires y experiencias, lo cual estaría asociado a lo femenino. Esteban (2011) explica que el terreno de los afectos y la expresión sobre los mismos están vinculados, en las culturas occidentales, a la construcción identitaria de las mujeres. En la construcción de la masculinidad mexicana se vería como una fisura a la misma demostrar que buscan activamente encuentros eróticos y/o afectivos.

\section{Conclusiones}

En este artículo reflexioné sobre las subjetividades posmodernas heterosexuales desde las dimensiones erótica y afectiva. Para tal fin analicé por qué Tinder dentro de un contexto de modernidad tardía -atravesado por características como la inmediatez, la falta de tiempo de libre por fuera del ámbito laboral y el miedo a la inseguridad y a la violencia como así también la preponderancia de las soluciones de mercado-, es apreciado por los/las entrevistados/as, de Ciudad de México y de Ciudad de Buenos Aires (con sus especificidades y similitudes), como un espacio de sociabilidad óptimo, en términos racionales de costo-beneficio y más allá de guiones románticos, para llevar a cabo encuentros eróticos y/o afectivos. Para tal fin examiné tres ejes: las percepciones que poseen los/as usuarios/as sobre la utilización de la aplicación; cuáles son las motivaciones que median en su uso (conseguir pareja, tener hijos/as, tener encuentros sexuales, conocer una ciudad) y la agencia femenina.

El hallazgo más sobresaliente que se desprende del artículo es el lugar central que posee la virtualidad al momento de sociabilizar en el contexto de modernidad tardía. Somos sujetos cyborgs (Haraway, 1991) cuyas vidas se experimentan en un onlife, un contínuum entre las dimensiones online y offline. Sin negar los efectos negativos que puede tener sobre la subjetividad el uso de las aplicaciones, y que aquí no han sido desarrollados en profundidad -a saber, la angustia por no sentirse deseado o la frustración de no poder encontrar lo que se busca-, considero que en un contexto de mayor fugacidad y donde el tiempo parece ser un valor cada vez más escaso, esta aplicación, que es parte del mercado erótico afectivo, permite la erotización y el encuentro con otros/as. Le ofrece a sus usuarios/as, según su propio testimonio, en términos racionales: seguridad, accesibilidad, comodidad y maximización del uso del tiempo. En otras palabras, desde la app estas subjetividades posmodernas, desligadas y precarias, sociabilizan y vehiculizan sus deseos. 


\section{Bibliografía}

" Ariño, Mabel (2007). "Familias tradicionales, nuevas familias". En Susana Torrado (Comp.), Población y bienestar en la Argentina del primero al segundo Centenario. Una historia social del siglo XX. Buenos Aires, Argentina: EDHASA.

" Ariza, Marina y de Oliveira, Orlandina (Coor.)(2004). Imágenes de la familia en el cambio de siglo. México D.F., México: Universidad Nacional Autónoma de México - Instituto de Investigaciones Sociales.

» Beck, Ulrich (1998). La sociedad de riesgo. Hacia una nueva modernidad. Barcelona, España: Paidós.

» Ben, Pablo e Insausti, Joaquín (2017). “¡Éramos tan diferentes y nos parecemos tanto!”. En José Javier Maristany y Jorge Luis Peralta (Comps.), Cuerpos Minados. Masculinidades en Argentina. La Plata, Argentina: Editorial de la Universidad Nacional de la Plata.

»Belmont Cortés, Edgar (2014) “La reforma laboral en México: La mitificación de la empresa y los ajustes en las relaciones laborales". Nueva antropología, núm. 27.

" Blumer, Markie, Ansara, Gavriel y Watson, Courtney (2013) "Cisgenderism in Family Therapy: How Everyday Clinical Practices Can Delegitimize People's Gender Self-Designations". Journal of Family Psychotherapy, núm. 24.

» Burin, Mabel (2003), "El deseo de poder en la construcción de la subjetividad femenina. El 'techo de cristal' en la carrera laboral de las mujeres". En Almudena Hernando Gonzalo (Coord.), ¿Desean las mujeres el poder? Cinco reflexiones en torno a un deseo conflcitivo. Madrid, España: Minerva Ediciones.

"Caetano, Gerardo (2010). Gobernabilidad Democrática y Ciudadanía en América del Sur. Impactos Políticos de la Crisis Global., Costa Rica: Flacso.

"Cerrutti, Marcela y Binstock, Georgina (2009). "Familias latinoamericanas en transformación: desafíos y demandas para la acción pública”, CEPAL-Serie Políticas Sociales, núm. 147.

»Cheresky, Isidoro (2011). Ciudadanía y legitimidad democrática en América Latina. Buenos Aires, Argentina: Prometeo.

»Collins, Randall (2009). Cadenas de rituales de interacción. Barcelona, España: Anthropos, UAM-Azcapotzalco, UNAM-FCPY, Editorial Universidad Nacional de Colombia.

" Conapo (Consejo Nacional de Población) (2002). La situación demográfica en México. México D.F., México: Consejo Nacional de Población.

»Connell, Raewyn (1995). Masculinities, Berkeley, Estados Unidos: University of California Press.

»Connell, Raewyn (2002). Gender. Cambridge, Inglaterra: Polity Press.

»De Certeau, Michel (1996). La invención de lo cotidiano. El arte de hacer. México: Universidad Iberoamericana.

»De Lauretis, Teresa (1989) “La tecnología del género” Revista Mora, núm. 2, 1996. (Traducción de Ana María Bach y Margarita Roulet, tomado de Technologies of Gender. Essays on Theory, Film and Fiction. London Macmillan Press). 
"De Oliveira, Orlandina (1994). “Experiencias matrimoniales en el México urbano: la importancia de la familia de origen”. Estudios Sociológicos, núm. 13.

»Dever, Maryanne and Saugeres, Lisa (2004). “I Forgot to Have Children!" Untangling Links between Feminism, Careers and Voluntary Childlessness“. Journal of the Association for Research on Mothering, núm. 6.

»Elizalde, Silvia y Felitti, Karina (2015). “,Vení a sacar a la perra que hay en vos": pedagogías de la seducción, mercado y nuevos retos para los feminismos”. Revista Interdisciplinaria de Estudios de género, núm. 1.

»Encinas Ferrer, Carlos (2009). “Neoliberalismo y distribución del ingreso en los Estados Unidos de América”. Problemas del desarrollo, núm. 40.

»Esteban Galarza, Mari Luz (2011). Critica al pensamiento amoroso. Barcelona, España: Bellaterra.

»Esteinou, Rosario (2010). “Las relaciones de pareja en el México moderno". Casa del Tiempo, núm. 25.

"Featherstone, Mike y Mike Hepworth (1991). The Body. Social Process and Cultural Theory. Londres, Inglaterra: Sage.

»Flores Cruz, Ramiro (s/f). El crecimiento de la población argentina. Instituto de Investigaciones Gino Germani, Facultad de Ciencias Sociales, Universidad Nacional de Buenos Aires. Recuperado de <http://www.webiigg.sociales.uba. ar/pobmigra/archivos/ramiroflores/crecimiento.pdfs.

» Hakim, Catherine (2010). “Erotic capital”. European Sociological Review, núm. 20.

» Haraway, Donna (1991). Ciencia, cyborgs y mujeres. La reivindicación de la naturaleza. Madrid, España: Cátedra.

»Herrera Gómez, Coral (2012). Amor romántico: Lo personal es politico. La dimensión socioeconómica de los afectos, Madrid, España: El Rincón de Haika.

»Hochschild, Arlie (1983). The Managed Heart: commercialization of human feeling. Berkeley, Estados Unidos: University of California Press.

»Illouz, Eva (2007). Intimidades congeladas, Buenos Aires, Argentina: Katz.

» Illouz, Eva (2009). El consumo de la utopía romántica. El amor y las contradicciones culturales del capitalismo. Buenos Aires, Argentina: Katz.

» Illouz, Eva (2012). Por qué duele el amor. Una explicación sociológica, Buenos Aires, Argentina: Katz.

" Jelin, Elizabeth (1989). "El celibato, la soledad y la autonomía personal: la elección personal y restricciones sociales”. Estudios Demográficos y Urbanos, núm. 4.

» Jelin, Elizabeth (2010). Pan y afecto. La transformación de las familias. Buenos Aires, Argentina: Fondo de Cultura Económica.

» Klinenberg, Eric (2012). Going Solo: The Extraordinary Rise and Surprising Appeal of Living Alone. New York, Estados Unidos: The Penguin Press.

"Maffesoli, Michel (2009). El reencantamiento del mundo. Una ética para nuestro tiempo. Buenos Aires, Argentina: Dedalus.

» Mazzeo, Victoria (2010). "Nupcialidad y familia”, en Alfredo Lattes (Coord.), Dinámica de una ciudad. Buenos Aires, 1910-2010. Buenos Aires, Argentina: Dirección General de Estadística y Censos.

" Meccia, Ernesto (2012). "Subjetividades en el puente. El método biográfico y el análisis microsociológico del tránsito de la homosexualidad a la gaycidad". Revista Latinoamericana de Metodología de la Investigación Social, núm. 4. 
» Mier y Terán, Martha y Virgilio Partida (2001). “Niveles, tendencias y diferenciales de la mortalidad”. En J. Gómez de León y C. Rabell (Coords.). La población en México. México: Consejo Nacional de Población/Fondo de Cultura Económica.

"Parnreiter, Christof (2002). "Ciudad de México: el camino a una ciudad global”. EURE (Santiago), núm. 28.

"Pérez Amador, Julieta (2008). "Análisis multiestado multivariado de la formación y disolución de las parejas en México". Estudios Demográficos y urbanos, núm. 3 .

"Rizo García, Marta (2015). “Interacción y emociones. La microsociología de Randall Collins y la dimensión emocional de la interacción social”. Psicoperspectivas, vol. 14 (núm. 2).

»Rodríguez, Santiago Andrés (2016). “En busca de la 'media naranja': La construcción social de las preferencias matrimoniales en el Área Metropolitana de Buenos Aires y en la Ciudad de México". Conformación de parejas y desigualdad social. Un análisis comparativo del Área Metropolitana de Buenos Aires y la Ciudad de México (Tesis de doctorado publicada), Centro de Estudios Sociológicos - El Colegio de México, Ciudad de México.

»Salazar, Francisco (2004). “Globalización y política neoliberal en México”. El Cotidiano, núm. 20.

"Sánchez Castañeda, Alfredo (2014). Los diez temas fundamentales de la reforma laboral en materia individual. México: FES.

"Sautu, Ruth (2016). "La formación y la actualidad de la clase media argentina". En Gabriel Kessler (Comp.), La Sociedad argentina hoy. Buenos Aires, Argentina: Siglo XXI.

"Serano, Julia (2016). Whipping Girl: A Transsexual Woman on Sexism and the Scapegoating of Femininity. Berkeley, Estados Unidos: Seal Press.

»Thompson, Edward (1979). Tradición, revuelta y conciencia de clase. Estudios sobre la crisis de la sociedad pre industria., Barcelona, España: Crítica.

»Tin, Louis-Georges (2012). La invención de la cultura heterosexual. Buenos Aires, Argentina: El Cuenco del Plata.

»Torrado, Susana (2007). Población y bienestar en la Argentina del primero al segundo Centenario. Una historia social del siglo XX. Buenos Aires, Argentina: EDHASA.

\section{Fuentes documentales}

» Andrea, lorio [RadioLatinaFM101.1], Andrea lorio en Azzaro Al Horno [Archivo de video], 11 de febrero 2016. Recuperado de <https://www.youtube.com/ watch?v=PYuXC24KAZA>.

»Andrea, lorio [ImagenRadio], Entrevista al director de negocios de Tinder ¡Qué tal Fernanda! [Archivo de video], 14 de junio de 2016, <https://www.youtube. com/watch?v=VWSvMurEsws $>$.

»Censos 2000 y 2010, Instituto Nacional de Estadísticas y Geografía de México (INEGI).

" Garza, Scarlett (presentadora), Más Milenio [programa de noticias de TV]. Milenio Televisión (productor ejecutivo). México es el segundo lugar de Tinder Latinoamérica. Entrevista con el director de Tinder Latinoamérica por Scarlett 
Garza. Ciudad de México, México: Milenio Televisión, 17 de junio de 2016, <http://tv.milenio.com/tendencias/tinder-latinoamerica-andrea-lorio-director-tinder-america-latina_3_757754241.html>

»Organización Mundial de Turismo, Datos, 2016. Recuperado de <http:// www2. unwto.org/es/content/datos-o>.

» Rua, Martín (13 de febrero de 2016). “Los argentinos tienen más éxito en Tinder que el promedio de los usuarios", La Nación. Recuperado de <http:// www.lanacion.com.ar/1870504-los-argentinos-tienen-mas-exito-en-tinder-queel-promedio-de-los-usuarios>.

»Secretaria de Turismo (2016) Evaluación de desempeño de los destinos turísticos en el marco de los Convenios de Coordinación en materia de Reasignación de Recursos (CCRR). Análisis del desempeño turístico local. Modelo de satisfacción. México: Secretaria de Turismo, CONACYT, CESTUR. 